\title{
PREFERÊNCIA VISUAL DE PAISAGENS DO PARQUE MUNICIPAL DO PASSAÚNA, CURITIBA, PR
}

\author{
VISUAL PREFERENCE OF LANDSCAPES OF PASSAUNA MUNICIPAL PARK, CURITIBA, PR
}

\section{VIEIRA, Carolina H. S. D.}

Arquiteta e Urbanista, Mestranda em Engenharia Florestal pela Universidade Federal do Paraná.

E-mail: carolinahaddad@gmail.com

\section{KOZERA, Carina}

Bióloga, Doutoranda em Engenharia Florestal pela Universidade Federal do Paraná.

E-mail: kozera23@yahoo.com

\section{BIONDI, Daniela}

Engenheira Florestal, Paisagista, Dra. Professora do Departamento de Ciências Florestais da Universidade Federal do Paraná. E-mail:dbiondi@floresta.ufpr.br

\section{RESUMO}

A análise da preferência de paisagens pode ser um excelente instrumento tanto para 0 planejamento como para a intervenção em áreas utilizadas com fins recreativos e turísticos, como em parques. $O$ presente trabalho teve por finalidade fazer uma avaliação pelo método direto (tendo o público como agente valorador), a fim de investigar as preferências visuais referentes a paisagens do Parque Municipal do Passaúna, município de Curitiba (PR). Como representantes das paisagens foram utilizadas fotografias, acompanhadas de um questionário com itens relacionados às paisagens e aos entrevistados. A maioria dos entrevistados foi do sexo feminino (58\%), de faixa etária até 25 anos (42\%) e escolaridade terciária (51\%). Os fatores que se relacionaram à preferência visual foram o grau de escolaridade e a preferência por cores. $O$ principal aspecto indutor de preferência visual está associado à naturalidade da paisagem, de forma que as paisagens de maior aceitação foram aquelas que apresentaram melhor aspecto de conservação do meio, naturalidade, equilíbrio e harmonia entre os elementos constantes na cena.

Palavras-chave: Análise da paisagem, componentes da paisagem, áreas verdes.

\begin{abstract}
The analysis of landscape preferences may be an excellent instrument so much for the planning as for the intervention in areas used with recreational and tourist purposes, as in parks. The present work had for purpose to do an evaluation by the direct method (using the public as the agent that values), in order to investigate the visual preferences referring to landscapes of Passaúna Municipal Park, municipal district of Curitiba (PR). In order to represent the landscapes, photographs has been used, followed by a questionnaire with items related to the landscapes and to the interviewed ones. Among the interviewed ones, most of them are women (58\%), belong to age group up to 25 years (42\%) and have tertiary education (51\%). The factors that linked to the visual preference has been the education degree and the color preference. The main inductive aspect of visual preference are associated to the naturalness of the landscape, so that the landscapes of larger acceptance has been those that has better presented aspects of conservation of the environment, naturalness, balance and harmony between the elements in the scene.
\end{abstract}

Key words: Analysis of the landscape, components of the landscape, green areas. 


\section{Introdução}

Desde o século XIX o tema "paisagem" vem sendo discutido para se entender as relações sociais e naturais em um determinado espaço. Inicialmente, a maioria dos conceitos desenvolvidos estavam vinculados a determinadas abordagens filosóficas, ligados ao positivismo. Hoje a idéia merece mais atenção pela avaliação ambiental e estética (SCHIER, 2003).

Dos muitos conceitos atribuídos à paisagem, interpretados por profissionais de diversas áreas, os mais atuais a definem como expressão do produto de interação dos componentes geológicos, dos fatores geomorfológicos, bióticos e antrópicos, através do tempo, refletindo o registro acumulado da evolução biofísica e da história das culturas precedentes (UICN, 1984; ROCHA, 1995).

Para GOLDENSTAIN apud PIRES (1992), o que existe hoje são paisagens onde a interferência da ação antrópica se faz sentir em diferentes graus de intensidade, em detrimento do tipo de paisagem que se convencionou chamar de quadro natural.

O estudo das paisagens tem suas origens no terceiro e quarto decênio do século XX, quando a humanidade começou a ter consciência de que pertence e depende do meio em que se encontra para viver. Surge, então, a problemática referente à conservação da paisagem, e os estudos relacionados a ela, inicialmente desenvolvidos por geógrafos e depois por outros especialistas (BOLÓS E CAPDEVILA, 1992).

Nas últimas décadas, foram realizadas inúmeras tentativas para restabelecer a visão integrada da paisagem, através da elaboração de novos métodos, abordagens e formas de interpretação. Devido a isso, a paisagem também vem sendo enfocada como um fenômeno sob a ótica humanística, que procura valorizar a experiência do indivíduo e do grupo visando compreender a percepção, a conduta e o sentimento dos indivíduos em relação ao ambiente, lugares e às paisagens. Estes estudos têm se destacado por expressarem o gosto, a preferência e os vínculos afetivos dos seres humanos e de suas comunidades para com os lugares e suas paisagens (LORUSSO, s/d).

Com relação à percepção, está condicionada a fatores inerentes ao próprio indivíduo (capacidade imaginativa, mecanismos de associação), a fatores educativos e culturais, e a fatores emotivos, afetivos e sensitivos, derivados das relações do observador com o ambiente (CANTERAS, 1992). Depende das relações observador-paisagem e da visibilidade do território, sendo que distância, posição do observador, condições atmosféricas, iluminação ou até tempo de duração da observação podem modificar a visão da mesma (MOPU apud PIRES, 1992).

Assim, avaliação ou valoração da qualidade visual da paisagem refere-se geralmente a um exercício comparativo, com muita subjetividade (LAURIE, 1976). Para um estudo efetivo da avaliação paisagística devem ser considerados os aspectos relacionados com o exercício de sensibilidade humana, de ordem estética e psicológica, sendo atualmente estudadas as relações entre as características da paisagem e os sentimentos que suscita (BOLÓS Y CAPDEVILA, 1992).

A análise da preferência de paisagens pode ser um excelente instrumento tanto para o planejamento como para a intervenção em áreas utilizadas com fins recreativos e turísticos, como os parques. Além disso, o entendimento da escolha de paisagens pela presença de determinados elementos que compõem certos cenários ajuda a criar modelos de paisagens que têm mais afinidades com o homem.

Assim, utilizando fotografias de paisagens do Parque Municipal do Passaúna - Curitiba (PR), este trabalho teve como objetivo analisar a preferência visual de um grupo de pessoas para obter os seguintes objetivos: 
a) Identificar paisagens que mais e menos agradavam o observador;

b) Identificar nas paisagens possíveis elementos que poderiam influenciar na preferência visual de paisagens;

c) Analisar o perfil das pessoas entrevistadas, relacionando-os com suas respectivas preferências visuais;

d) Investigar a existência de relação entre o perfil dos entrevistados e as preferências visuais das paisagens.

\section{Materiais e métodos}

A avaliação visual da paisagem foi realizada no Parque Municipal do Passaúna, localizado na região metropolitana do município de Curitiba, Estado do Paraná. Inaugurado em 10 de março de 1991, o parque possui uma área de $6.500 .000 \mathrm{~m}^{2}$ situada à margem da represa do rio Passaúna, responsável pelo fornecimento de $1 / 3$ da água consumida em Curitiba. Beirando o lago da represa, existe um caminho pavimentado com aproximadamente $3,5 \mathrm{~km}$, ao longo do qual podem ser observadas espécies da fauna e da flora, choupanas, recantos para pesca e para diversão de crianças, uma antiga olaria que funcionava na região, ancoradouros de barcos e um mirante de $46 \mathrm{~m}$ de altura e $27 \mathrm{~m}$ de comprimento, a partir do qual é possível uma visão panorâmica da área (PARANÁ, 1994).

A análise de preferência visual foi realizada pelo método direto em que, segundo PIRES (1992), o agente valorador pode ser o público em geral, grupos representativos da sociedade ou profissionais paisagistas. A paisagem analisada pode ser representada por fotografias, filmes, diapositivos e gravuras.

Para este trabalho foram utilizadas fotografias que, de acordo com BOLÓS Y CAPDEVILA (1992), são atualmente instrumentos que facilitam a análise, pela praticidade, economia de tempo e de trabalho, bem como pela padronização das análises.

De um conjunto de fotografias, foram selecionadas cinco, consideradas representativas dos locais mais freqüentados por visitantes do parque e que possuíam características distintas. $\bigcirc$ componente da paisagem "água" foi comum em todas as paisagens, em função de o parque ter em seu centro uma represa.

As paisagens selecionadas foram previamente analisadas (fotografias 1, 2, 3, 4 e 5) seguindo os princípios de composição paisagística de BIONDI (1990) (tabela 1).

Tabela 1: Resumo da Análise das Fotografias

\begin{tabular}{c|c|c|c|c}
\hline \multirow{2}{*}{ Fotografia } & \multicolumn{4}{|c}{ Síntese da Composição Paisagística } \\
\cline { 3 - 5 } & \multirow{2}{*}{ Dominância } & \multirow{2}{*}{ Contraste } & \multicolumn{2}{c}{ Componentes } \\
\cline { 3 - 5 } & & linha horizontal & Dominantes & Contrastantes \\
\hline 01 & linha horizontal/cor azul & - & água & palmeiras \\
\hline 02 & corverde & forma/linha/cor & água/vegetação & ponte \\
\hline 03 & corverde & linha/cor & vegetação & ponte/casa \\
\hline 04 & corverde & linha/cor & vegetação & trilha \\
\hline 05 & \multicolumn{3}{c}{}
\end{tabular}

Fotografia $n^{\circ} 1$ : Paisagem com predominância de água; possui mais de 2 planos de perspectivas; no $1^{\circ}$ plano tem-se um espelho $d^{\prime}$ água refletindo as palmeiras plantadas numa pequena península; o único elemento vertical é formado pelo conjunto de palmeiras; no último plano só se percebe uma silhueta / linha; marcada pelo artificialismo da disposição das palmeiras e do gramado. 


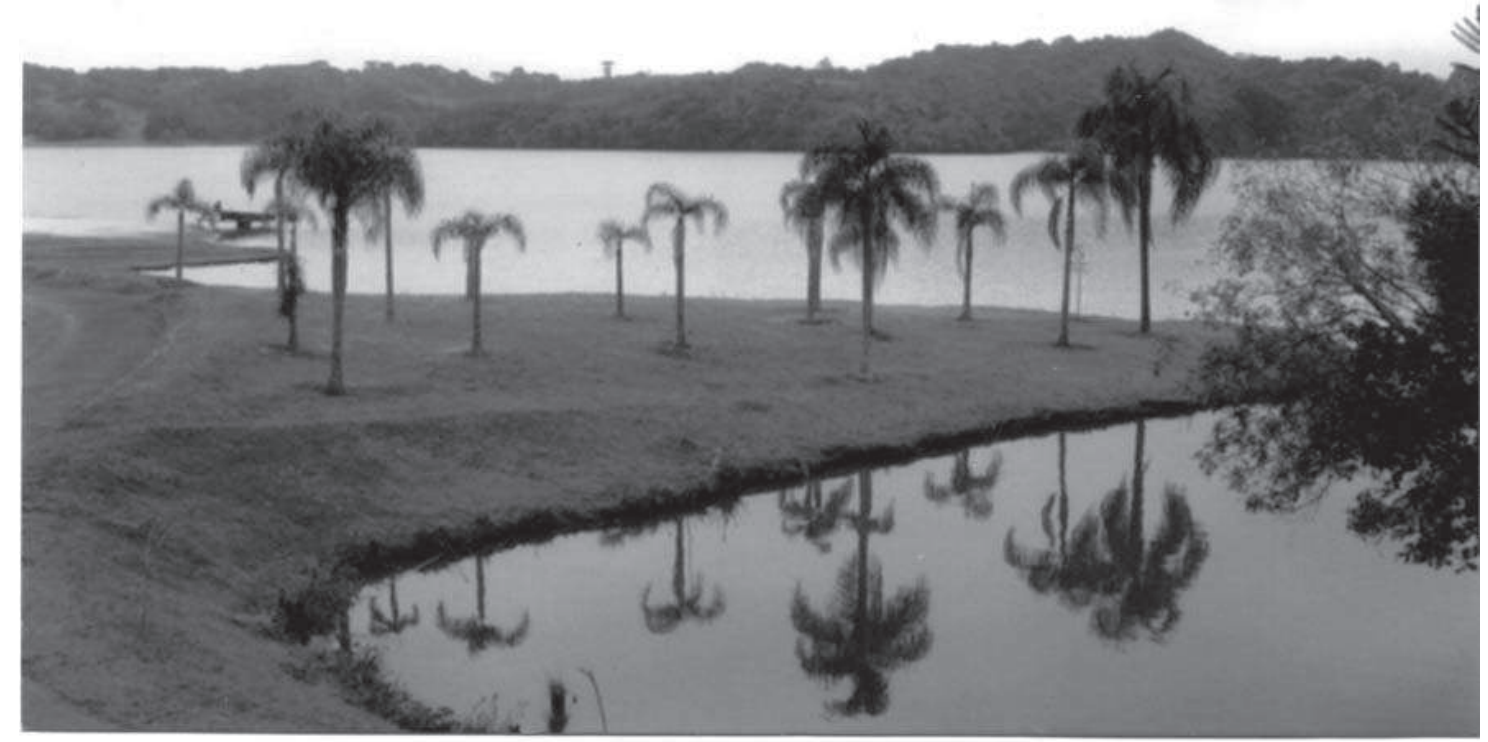

Figura 1: Paisagem panorâmica; predominância da água; não há nenhum contraste visual, a não ser parte do teto de um mirante (cor marrom claro), marcada pelo naturalismo das linhas (curvas) e vegetação



Figura 2: Paisagem com o 1ํ e o 2o planos detalhados; componente contrastante - a ponte de madeira que divide a paisagem em água/vegetação; mostra dinamismo (movimento da água e das copas das árvores, pessoas andando e efeitos de luz e sombra); marcada pelo naturalismo da vegetação e o contraste da ponte (forma/linha/cor); a cor verde domina a paisagem 


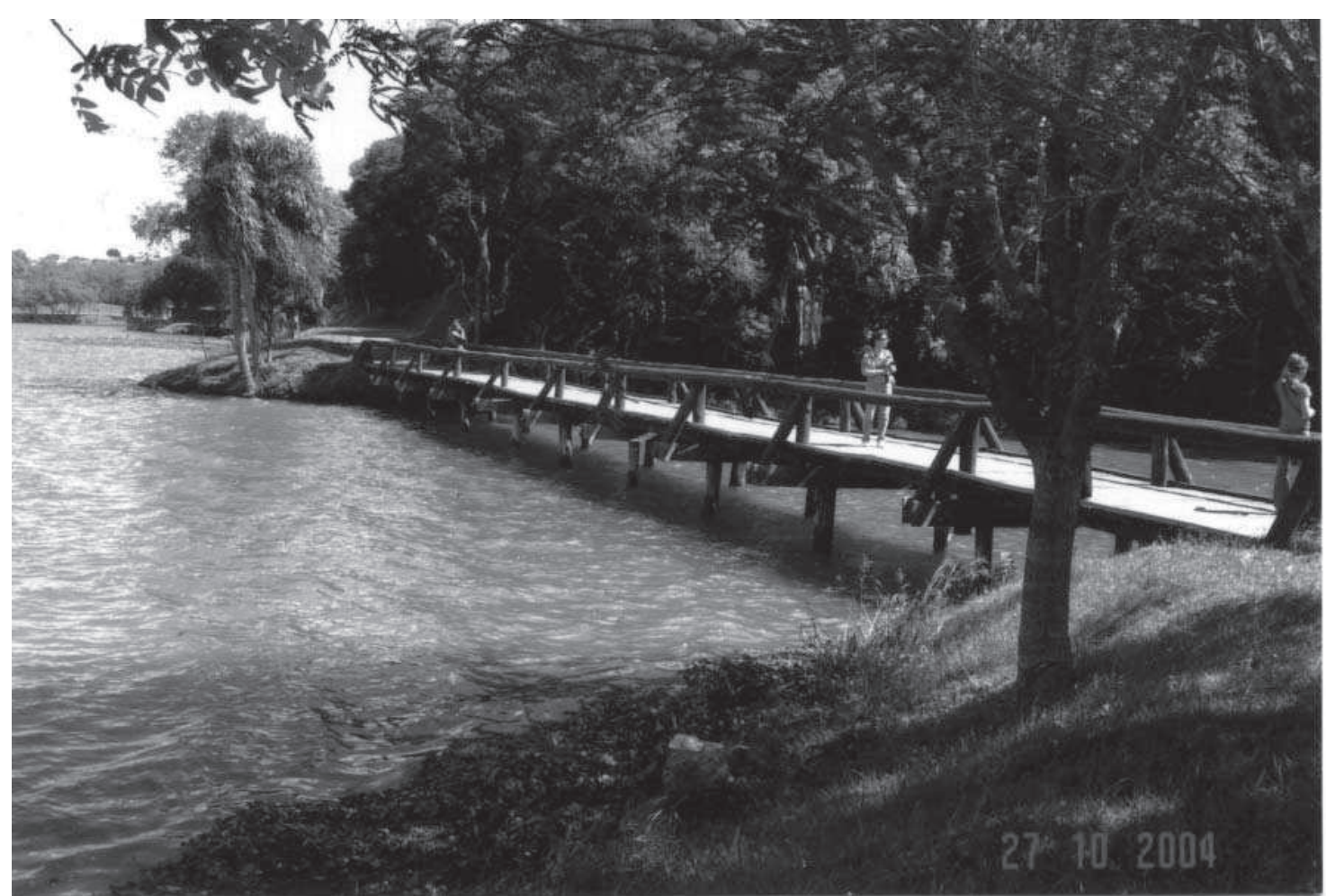

Figura 3: Paisagem marcada por três planos; a vegetação domina a cena; a ponte e a casa são componentes contrastantes, pela cor e linhas convergindo para o início do 2o plano (base do morro); o verde claro do gramado do 3o plano ajuda a salientar os diferentes tons de verde e formas de copas das árvores.

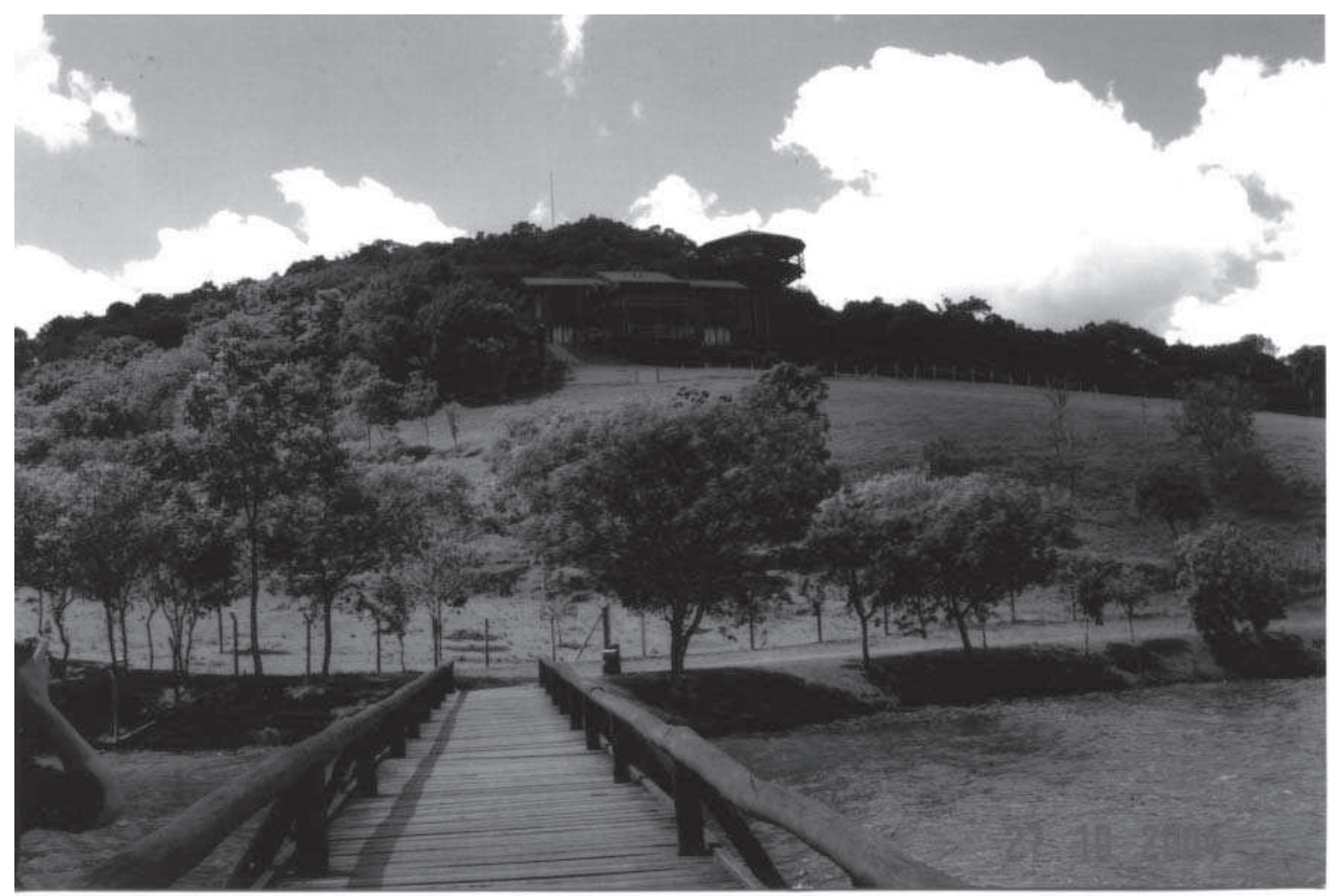

Figura 4: Paisagem marcada por uma trilha ou caminho sinuoso com diferentes planos (trilha, laterais e fundos); possui dinamismo pelo efeito de luz e sombra projetado no caminho; mostra com evidência um lado com brilho (iluminado) e um lado sem brilho (com sombra); a água fica indefinida ao fundo das árvores em um lado da trilha 


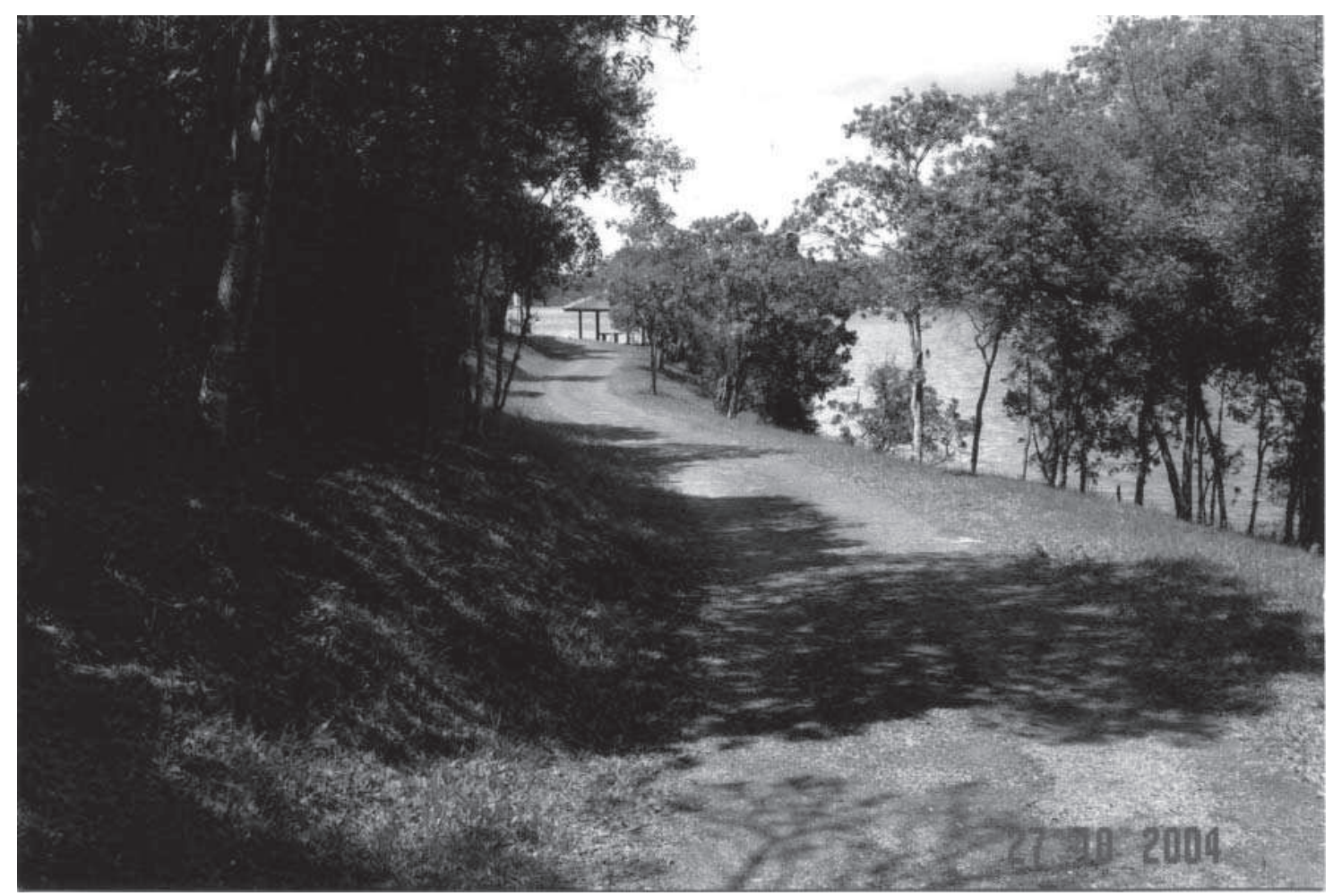

Para acompanhar as fotografias, foi elaborado um questionário para ser aplicado ao público, a respeito das paisagens e dos próprios entrevistados.

Com relação aos entrevistados, buscou-se identificá-los através de questões sobre a faixa etária, o gênero, o nível de escolaridade, a profissão ou área de trabalho, a cor preferida, a prática de atividades esportivas e preferências quanto a destinos de viagens e passeios (lugares naturais ou urbanizados).

Quanto às preferências visuais, para identificá-las, foram elaboradas questões objetivas, investigando, por exemplo, qual das paisagens apresentadas (representadas pelas fotografias) mais e menos agradou, e quais os elementos ou outros motivos que contribuíram para tais escolhas.

\section{Resultado e discussão}

\subsection{Perfil dos entrevistados}

Entre os entrevistados, a maioria são do sexo feminino (58\%) e apresentam idade até 25 anos (42\%).

Quanto à escolaridade, a maior proporção de entrevistados (51\%) apresenta o terceiro grau, sendo que destes, a maioria está na faixa etária entre 19 e 25 anos e se constituem principalmente de profissionais liberais (biólogos, engenheiros florestais, agrônomos, nutricionistas, entre outros). Os entrevistados com escolaridade secundária (31\%) possuem sua maioria na faixa etária até 18 anos, constituindo-se principalmente de estudantes e donas-de-casa. Com relação aos entrevistados que estão cursando ou já concluíram o primeiro grau, correspondem à minoria (18\%). Apresentam idade até 18 ou acima de 50 anos e se constituem principalmente de estudantes, donas-de-casa e comerciantes.

Com referência à preferência quanto a destinos de viagens e passeios, a maioria dos entrevistados manifestou preferência por áreas rurais e naturais, em oposição a áreas urbanas. Da mesma forma, a maioria prefere lugares com rios, cachoeiras ou mar como atrações de passeios e 
viagens. Isto pode ser explicado por TUAN (1980), que afirma que paisagens mais naturais são permanentemente atrativas, fazendo parte do imaginário humano como lugares ideais.

Quanto à questão de o entrevistado já haver visitado o Parque Municipal do Passaúna, constatou-se que a maioria não o conhecia. No entanto, a familiaridade com as paisagens foi bastante pronunciada, tendo sido declarada na maioria das respostas $(51 \%)$ e remetida principalmente a parques urbanos localizados na cidade de Curitiba - PR.

\subsection{Escolha das paisagens e preferência visual}

As paisagens representadas pelas fotografias de número 4 e 2 foram indicadas como preferidas pela maioria dos entrevistados e as de número 1 e 5 apresentaram maior índice de rejeição (Figura 1).

Com relação às preferidas, na fotografia 4 a presença da casa e da ponte sobre a água da represa foram os elementos preferidos pelos entrevistados. Com relação à casa, a sua indicação esteve relacionada com a posição, da qual é possível uma visão ampla da represa. Além disto, o aspecto de fazenda ou área conservada da paisagem foi destacado.

Na fotografia 2 a aparência do lugar e a dominância do elemento água, juntamente com a vegetação, foram os motivos mais apontados para a preferência. Nota-se, a partir desses dados, uma valorização da presença de elementos naturais, como a água e a vegetação nas paisagens. E, na fotografia 4, à valorização dos elementos naturais, inclusive, pode estar associada a apreciação dos elementos antrópicos citados (a casa e a ponte). De forma que estes não são apreciados apenas por si mesmos, mas principalmente pela condição em que se apresentam: pela sua inserção e pelo que oferecem. A inserção desses elementos em seu entorno, apesar de contrastante, é harmônica, o que pode ser verificado pela tecnologia de construção da ponte (feita em madeira) e da casa (com bastante uso de madeira e transparências); pela proximidade desses elementos com elementos naturais (a água sob a ponte e a mata perto da casa); e pela adaptação da casa à topografia do terreno. Esses fatores transmitem a sensação de que esses elementos antrópicos convivem pacificamente com seu entorno, sem agredir o meio no qual estão inseridos. E o que oferecem é um contato ainda mais íntimo com a natureza: a vista privilegiada dos elementos naturais (água, vegetação) oferecida pela posição da casa; e a possibilidade oferecida pela ponte de se estar sobre as águas da lagoa, transformando o expectador em participante da própria cena natural. Assim, pode-se concluir que, além da contemplação, a interação harmônica do ser humano com elementos da natureza é um fator almejado pelos entrevistados.

Quanto às paisagens indicadas como as que menos agradaram (fotografias 1 e 5), o aspecto de artificialidade foi o maior responsável pela rejeição. Nesse sentido, foram citados: a falta de sombras, escassez de vegetação arbórea nativa, a presença de gramados e de palmeiras plantadas, a artificialidade do ambiente, a aparência monótona da água e do céu, e a presença de um caminho pavimentado utilizado para a circulação de pessoas.

Mais uma vez, transparece a preferência por elementos naturais e a conseqüente rejeição pela artificialidade. Isso fica evidente, por exemplo, na diferença de impressão causada pela ponte da fotografia 4 e o caminho da fotografia 5. A ponte foi citada como elemento determinante de preferência, enquanto o caminho foi indicado como elemento de rejeição. Ambos são elementos de passagem, de trânsito de pedestres, e se constituem em elementos antrópicos inseridos no meio natural. No entanto a ponte é construída em madeira (material natural) e o caminho em concreto (material artificial). Isso também fica evidente na rejeição das paisagens em função da escassez de certos elementos naturais: falta de sombra - que é um indicativo de vegetação arbórea - e escassez de vegetação nativa. 
No caso das palmeiras, a artificialidade pode ser atribuída ao paralelismo formado pelos troncos, perfeitamente verticais (reforçado pelo reflexo na água), e à sua disposição regular. Além disso, a palmeira tem sua imagem associada a paisagens de litoral, o que criaria uma incoerência visual.

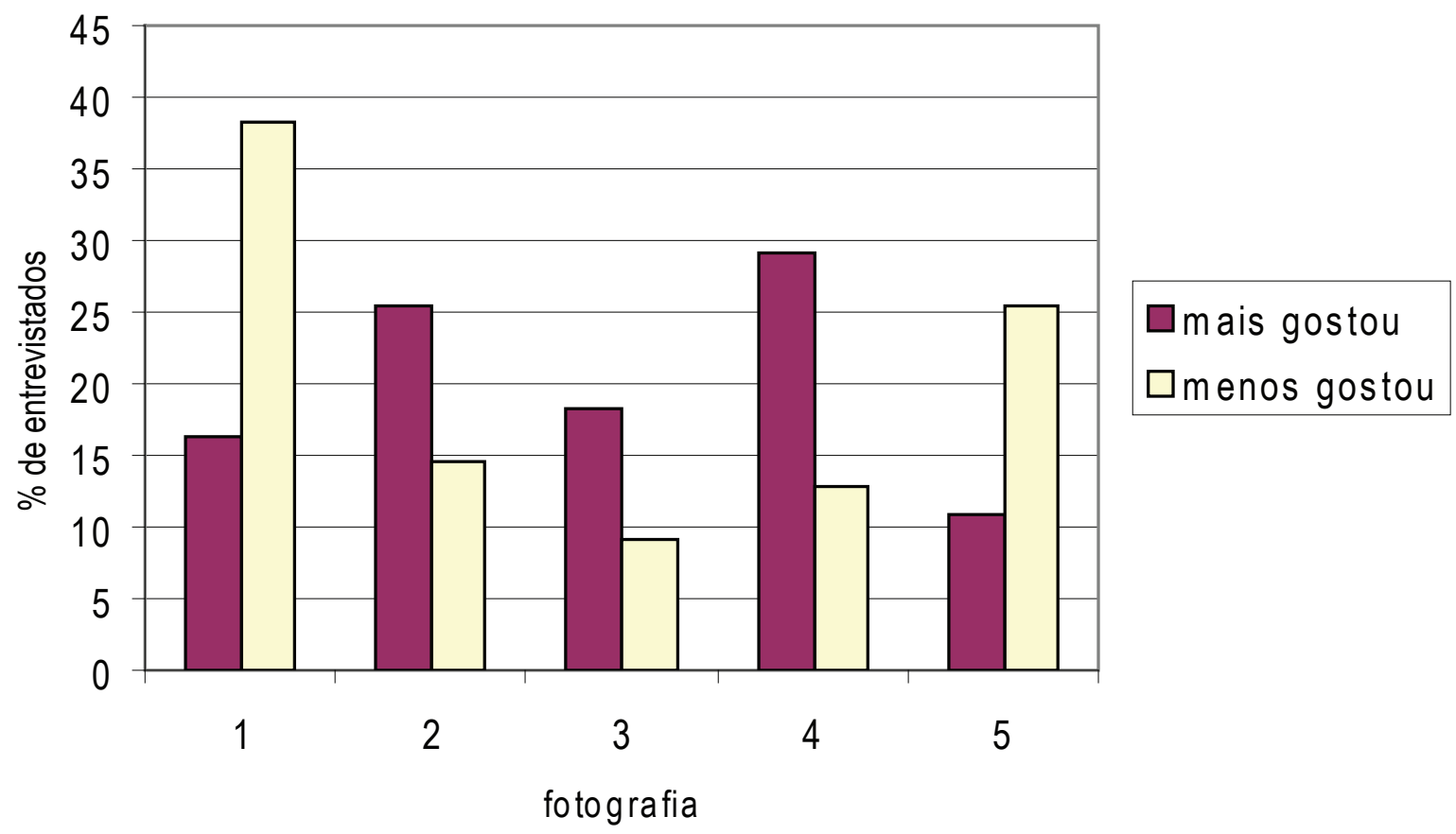

Quadro 1: Preferência visual das paisagens (representadas pelas fotografias) do Parque Municipal do Passaúna

\subsubsection{Preferência visual relacionada à escolaridade}

A respeito de uma possível relação entre o grau de escolaridade e a preferência visual de determinada paisagem, os dados obtidos não apresentaram relevância, de forma que em todos os graus de escolaridade houve distribuição relativamente homogênea das preferências. Uma pequena variação houve no grupo de nível terciário, em que a paisagem da fotografia 4 obteve um maior número de escolha como fotografia que mais agradou, tendo como o motivo mais citado para isto a presença de construção, ou seja, uma casa inserida no meio natural.

Com relação à rejeição, houve relativa homogeneidade nos graus primário e secundário de escolaridade. No grau terciário houve relevante predominância da escolha da fotografia de número 1, sobre a qual destacaram-se queixas em relação às palmeiras (principalmente em função de gosto pessoal), à pouca quantidade de sombra e à monotonia do ambiente.

Esses dados mostram que, entre as pessoas de escolaridade terciária, houve uma tendência à valorização da construção (casa) em meio ao ambiente natural e uma rejeição à presença de palmeiras, ao pouco sombreamento e à monotonia. $\bigcirc$ destaque dado à casa em detrimento de outros elementos pode ser explicado pela percepção de que esta está inserida harmonicamente no meio, sem desrespeitar a natureza, ao mesmo tempo em que se encontra dentro do perímetro urbano de uma das maiores cidades do país. Isto seria uma valorização da intervenção humana ecologicamente correta e bem sucedida, extrapolando a idéia da conservação ambiental por si só. O maior grau de instrução, nesse caso, poderia ser responsável por uma valorização do desenvolvimento sustentável, da ecologia a serviço do homem. 


\subsubsection{Preferência visual relacionada a cores}

A preferência de cores não aparentou nenhuma relação direta com o perfil dos entrevistados. Observou-se grande heterogeneidade tanto de faixa etária, gênero, grau de escolaridade, prática de atividade esportiva, profissão ou preferência por áreas urbanas, naturais ou rurais dentro de cada grupo de preferência por determinada cor.

A escolha da cor rosa, em especial, foi a única da qual pode-se observar uma relação. $\bigcirc$ grupo de pessoas entrevistadas que indicaram esta cor foi representado somente por mulheres de até 18 anos que estão cursando o $2^{\circ}$ grau (estudantes), perfil identificado como o de "adolescente".

Do total de questionários aplicados, $47 \%$ dos entrevistados indicaram a cor azul como sendo preferida, seguida pela verde (16\%) e vermelha (11\%). Além destas, também foram citadas as cores branca, preta, rosa e a alaranjada, sendo estas duas últimas as de menor preferência.

Segundo AMARAL (1975), geralmente as pessoas que preferem a cor azul, associam-na com a cor do céu, remetendo a uma idéia do eterno, no espaço e no tempo.

Entre os entrevistados que indicaram a cor azul - o maior grupo em questão - 81\% declararam preferência por áreas naturais ou rurais, principalmente lugares com rios, cachoeiras ou mar. Quanto à preferência visual, foram indicadas as paisagens 2 e 3 como as que mais agradaram, e a 1 como a que menos agradou. Na paisagem 2 a lagoa e a vegetação, representada pela floresta, foram apontadas como os elementos que mais agradaram, e na paisagem 3, a água e a ponte. Com relação à paisagem 1, o tipo de vegetação com aspecto monótono e a ausência de sombra estão entre os motivos de desagrado, como foi também observado no total dos entrevistados, independentemente de preferência por cor.

Analisando-se as características de composição da paisagem de cada uma das fotografias e os elementos apontados pelos entrevistados, como fatores de agrado ou desagrado, pode-se associar a preferência de cor à preferência visual relativa à escolha das paisagens. A fotografia 2, por exemplo, foi uma das escolhidas pelo grupo de pessoas que preferem a cor azul. Esta fotografia corresponde a uma paisagem com dominância da cor azul (o céu e a água da represa). Já na fotografia 1, apesar de a paisagem ter uma dominância do componente água, as condições atmosféricas (céu nublado) não permitiram salientar a cor azul da água e do céu. Isto pode ser uma das hipóteses de rejeição dessa paisagem.

\section{Conclusões}

O principal aspecto indutor de preferência visual está associado à naturalidade da paisagem, de forma que as paisagens de maior aceitação foram aquelas que apresentaram melhor aspecto de conservação do meio, naturalidade, equilíbrio e harmonia entre os elementos constantes na cena.

As paisagens preferidas (fotografias 2 e 4), mesmo constituídas, em parte, por elementos artificiais ou contrastantes, representados pelas casas e a ponte, foram escolhidas pela sua harmonia no conjunto, isto é, pela sua perfeita integração na paisagem.

O gênero e a faixa etária dos entrevistados não tiveram relação direta com a escolha das paisagens, mas o grau de escolaridade e a preferência por cores tiveram relação com a preferência visual, podendo ter influenciado na escolha. 


\section{Bibliografia}

AMARAL, A. I. F. Estudo de cores. Viçosa: Universidade Federal de Viçosa, 1975.

BIONDI, D. Paisagismo. Recife: Universidade Federal Rural de Pernambuco, 1990.

BOLÓS Y CAPDEVILA, M. Manual de ciencia del paisage: Teoría, métodos y aplicaciones. Barcelona: Masson S. A., 1992.

CANTERAS, J. C. Introdución al paisaje: Metodologias de valoración. Apostila da disciplina de Estudos da Paisagem do curso de pós-graduação em Engenharia Florestal da Universidade Federal do Paraná. Curitiba: UFPR, 1992.

LORUSSO, D. C. Geomorfología e paisagem. Seminário apresentado na disciplina de Estudos da Paisagem do curso de pós-graduação em Engenharia Florestal da UFPR. Curitiba: UFPR, s/d.

LAURIE, M. An introduction to landscape architecture. Nova York: Elsevier, 1976.

PARANÁ. 1994. Paraná: Guia técnico de turismo. 4. ed. Curitiba: Secretaria Especial do Esporte e Turismo,

PIRES, P. S. Análise da paisagem na avaliação de impacto ambiental. Apostila da disciplina de Estudos da Paisagem do curso de pós-graduação em Engenharia Florestal da Universidade Federal do Paraná. Curitiba: UFPR, 1992.

ROCHA, C. H. Ecologia da paisagem e manejo sustentável em bacias hidrográficas: Estudo do rio São Jorge nos campos gerais do Paraná. 1995. 176p. Dissertação (Mestrado) - Universidade Federal do Paraná, Curitiba, 1995.

SCHIER, R. A. As concepções da paisagem no Código Florestal. 2003. 117p. Dissertação (Mestrado) - Universidade Federal do Paraná, Curitiba, 2003.

TUAN, Y. F. Topofilia: Um estudo da percepção, atitudes e valores do meio ambiente. São Paulo: Difel, 1980.

UICN (União Internacional para a Conservação da Natureza). Estratégia mundial para a conservação: A conservação dos recursos vivos para um desenvolvimento sustentado. São Paulo: Cesp, 1984. 